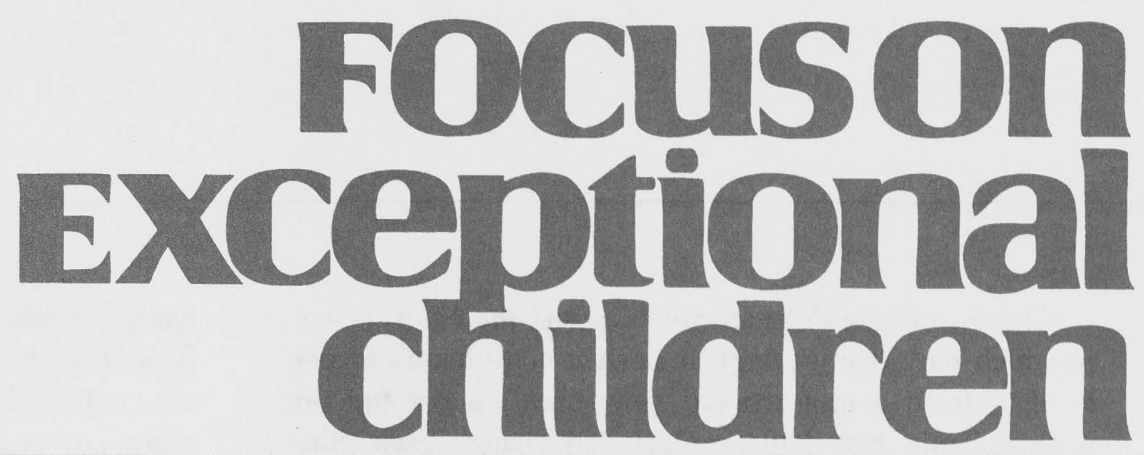

\title{
Risk, Families, and Schools
}

\author{
Barbara K. Keogh
}

For a number of years, my associates and I have been involved in the study of children at-risk for developmental and educational problems. I will not document the specific triumphs and vicissitudes of this journey, except to say that, like travel in a foreign land, we have learned to cope with problems in communication and understanding, we have experienced frustrations and fatigue, and, occasionally, even boredom. Our research travels have taken us on some wayward paths and into a number of blind alleys. Ours has been an interesting, if somewhat circuitous, journey.

\section{WHY STUDY RISK?}

Understanding risk has implications for clinical/educational decisions and for policy. What kind of educational programs should at-risk children receive? Where should we put our often limited resources? Insights from risk research also throw light on the workings of developmental processes in normally developing individuals, as well as those with problems. It should not surprise us that research has been accelerating that relates early risk to a range of problem conditions, and that many different kinds of risk have been identified. Preterm babies with very low birthweights are considered "at-risk." Children living in extreme poverty are viewed as "at-risk."

Rather than focusing exclusively on one kind of risk, current research efforts approach the study of risk from an interactional or transactional perspective, considering the child in context (Sameroff \& Chandler, 1975). This approach takes into account conditions both in the child and in the nature of the environments in which he or she lives. As an example, the recent volume Risk, Families and Competence (Lewis \& Feiring, 1998) includes chapters on divergent families, immigrant families, home environments, family-peer relationships, family typologies, children with developmental delays, and gifted children.

Barbara Keogh is with the Department of Psychiatry and Biobehavioral Sciences, University of California, Los Angeles. 
Clearly, children's characteristics and the environments in which they live are both important contributors to risk. Further, from a transactional view, they do not function independently but, rather, affect and change each other. Family conditions may intensify or ameliorate children's developmental or behavioral problems. Similarly, family experiences, peers, and teachers will influence children's learning problems.

Recognizing that context is a powerful contributor to risk does not negate the importance of in-child conditions but does make our understanding of risk more complex. Because the terms "risk" and "at-risk" are so broad, major issues in understanding have to do with definition and the specification of outcomes. Consider first how risk is defined.

\section{DEFINING RISK}

Broadly defined, risk identifies "negative or potentially negative conditions that impede or threaten normal development (Keogh \& Weisner, 1993, p. 4). Werner and Smith (1992) described risk factors as "biological or psychosocial

\section{FOCuson Exceptional children}

ISSN 0015-511X

FOCUS ON EXCEPTIONAL CHILDREN (USPS 203-360) is published monthly except June, July, and August as a service to teachers, special educators, curriculum specialists, administrators, and those concerned with the special education of exceptional children. This publication is annotated and indexed by the ERIC Clearinghouse on Handicapped and Gifted children for publication in the monthly Current Index to Journals in Education (CIJE) and the quarterly index, Exceptional Children Education Resources (ECER). The full text of Focus on Exceptional Children is also available in the electronic versions of the Education Index. It is also available in microfilm from Xerox University Microfilms, Ann Arbor, MI. Subscription rates: Individual, $\$ 30$ per year; institutions, \$40 per year. Copyright (C) 2000, Love Publishing Company. All rights reserved. Reproduction in whole or part without written permission is prohibited. Printed in the United States of America. Periodicals postage is paid at Denver, Colorado. POSTMASTER: Send address changes to:

Love Publishing Company

Executive and Editorial Office

P.O. Box 22353

Denver, Colorado 80222

Telephone (303) 221-7333

Karen Harris

University of Maryland

James Shriner

University of Illinois
Thomas Skrtic University of Kansas hazards that increase the likelihood of a negative developmental outcome in a group of people" (p.3). Ramey, Trohanis, and Hostler (1982) defined risk as "a comparative and relative term used to express the likelihood of a current or future development or handicap that, at present, is uncertain" (p. 8).

Central to these definitions is the recognition that risk is a probability statement. That is, early individual and environmental conditions are used to predict future outcomes. Risk is a useful term in that it does not necessarily imply the actual presence of a deficit or a disability. Rather, it suggests the possibility of subsequent problems. Thus, it is important to specify what constitutes early risk. Does the individual have a genetic or biological condition, such as chromosomal anomalies or perinatal organic insults? Or is risk present in the environment or the context in which the individual lives, such as poverty, disrupted families, or abusive parents? Many risk conditions likely are confounded or associated. For example, the possibility of peri- and neonatal problems may be greater if the mother does not receive proper prenatal medical care because she lives in poverty and services are not available. Identifying the risk conditions is only half of the equation, however.

To understand the significance of early risk, the antecedent conditions and their possible consequences both must be considered. Clearly stressful and negative early life conditions may have many possible consequences or outcomes, but certain risk indicators may be associated with problems at particular developmental periods and may be gender-related. Elderly individuals might be at-risk for Alzheimer's disease, adolescent boys for delinquency, women for breast cancer, young adults for drug and alcohol abuse. Important questions, then, have to do with at risk for what and when? School failure? Developmental delay? Delinquency? Alcoholism? Mental health problems? Thus, risk is understood best within a developmental framework, as the nature of problems may differ at different ages.

\section{PREDICTING OUTCOMES}

The path between early conditions and outcomes is not a single one, nor is it linear, and prediction from early conditions to specific outcomes is limited. Many experiences and opportunities affect a given individual's developmental path. These have to do with biological status, with environmental conditions, with opportunities and stresses, with traumatic events.

To illustrate: In current work at UCLA (Keogh, Bernheimer, \& Weisner, 2000) we have followed a group of children identified at age 3 as having developmental delays of unknown etiology. They are now 23 years old. Findings based on detailed follow-up of 30 individuals indicated that, 
for the group as a whole, there were continuing problems: 10 are in group placements, 15 are still living at home, fewer than 9 are employed. Yet, examination of individuals within the group documents a wide range of outcomes: 15 have basic or adequate reading skills, four are attending 2- or 4-year colleges, two have married, and one has started a family.

Thus, an important caution for making clinical decisions is that predictions from early risk signs are often valid for groups but are much less powerful for individuals within groups. Think of high-achieving people who spent their childhood years in poverty and in educationally disadvantaged circumstances. Think of children from high economic, "advantaged" situations who became involved in illegal or personally destructive behaviors. How can we explain these differences in outcomes? The question leads to consideration of protective factors in children's lives and to the concept of resilience.

\section{PROTECTIVE FACTORS}

Werner (1986) emphasized the importance of "environmental context variables that mediate the expression of potentially harmful biological and psychosocial events over time" (p. 18). Garmezy, Masten, and Tellegen (1984) considered protective factors as "dispositional attributes, environmental conditions, biological predispositions, and positive events that can act to contain the expression of deviance or pathology" (p. 109). Rutter $(1979,1987)$ proposed that protective factors have modulating or buffering effects on stressful events. Protective influences may have to do with the characteristics of the individual (e.g., positive temperament) or with the environment (e.g., stable family). And like risk factors, protective factors may differ across developmental periods and may be related to gender.

It should be noted that some uncertainty surrounds the issue of how to define protective factors and how they operate vis a vis risk factors. That is, are they best defined as the "flip side" of risk factors and, thus, effective only in response to risk? Or do they make independent contributions to child status regardless of risk conditions? Sameroff et al. (1998) argued that a better term for protective factors is promoting factors, identifying conditions that aid or contribute positively to a child's development.

Examples of promoting factors are a mother's good mental health and a positive family climate. Work by this research group has documented that "the more risk factors, the worse the outcomes; the more promotive factors, the better the outcomes" (p. 172). Thus, they underscore the importance of identifying protective influences as well as documenting risk conditions as proposed by Garmezy (1985).

When we think of risk as a probability statement, many factors, both positive and negative, clearly contribute to the development and achievement of individuals, whatever their group status. Some of these positive factors serve as protective or promotive influences, minimizing or mitigating the impact of risk conditions, thereby affecting predictions. Based on their review of risk research, Keogh and Weisner (1993) proposed four generalizations about prediction from early indicators:

\begin{abstract}
Prediction is more accurate for groups than for individuals within groups; the power of specific risk indicators varies relative to ecological and cultural context; risk conditions may be mediated by the presence of protective factors; outcome status varies according to the time and content of assessment. (p. 3)
\end{abstract}

\section{OPERATIONALIZING RISK AND PROTECTIVE FACTORS}

A number of conditions have been identified as contributing to risk for development and achievement. Similarly, protective influences have been defined. Real issues involve how to operationalize these variables and how to integrate them. In this article I consider briefly three aspects of risk and protective factors: early in-child signs, families, and schools.

\section{In-Child Risk Factors}

Clinicians and researchers alike have provided clear evidence that the probabilities of negative outcomes are increased when risk factors are present, and a number of conditions associated with negative outcomes at a later time have been identified. A good deal of research has focused on in-child risk conditions in the neonatal and perinatal periods.

Keogh and Bernheimer (1995) for example, found that 28 of 69 children with developmental delays at age 3 had histories of problems or distress perinatally or within 28 days after birth. These included preterm birth, low birthweight, anoxia, seizures, and medical conditions that required prolonged hospital stays. These findings are consistent with a large literature base that suggests that children with serious peri- and neonatal stresses may be at risk for subsequent developmental problems. Common early inchild conditions associated with risk are summarized in Table 1.

It is important to underscore that very early conditions may be, but are not always, associated with subsequent problems. Unless they are extreme, single risk indicators have limited prognostic or predictive power. Rather, prediction is more powerful when a multi-risk or an additive model is used (Sameroff, Seifer, Baldwin, \& Baldwin, 1993). That is, the more risk signs in the early years, the more likely is a negative outcome. Further, the impact of inchild biological risk conditions increases when the child is 


\section{TABLE 1 In-Child Early Risk Signs}

\author{
Preterm birth (37 weeks gestation or less) \\ Low birthweight (2500 grams or less) \\ One-minute Apgar scores (4 or less) \\ Asphyxia \\ Metabolic disorders \\ Infection \\ Intracranial hemorrhage \\ Delayed development at age 1 \\ Head circumference at age 1 \\ Difficult Temperament
}

Source: From Minimal Brain Dysfunction by P. L. Nichols \& T-C Chen (Hillsdale, NJ: Lawrence Erlbaum \& Associates, 1981); Risk and Protective Factors in the Lives of Children with High-incidence Disabilities, by E. E. Werner, in Developmental Perspectives on Children with High-incidence Disabilities (Mahwah, NJ: Lawrence Erlbaum Assoc., 1999). Pp. 15-22.

in a socioeconomic (SES) disadvantaged environment (Werner, 1993, 1999). This, of course, necessitates taking into account both child conditions and family circumstances.

\section{Family Risk and Protective Factors}

The impact of family, social, and economic conditions on negative outcomes has been well established. Compared to more economically advantaged children, those from poor families are less likely to succeed educationally, have poorer jobs as adults, and have more personal adjustment problems. Their early life conditions put them at-risk for later accomplishments.

A number of researchers have documented characteristics or variables that describe such families and the conditions surrounding them. For example, Sameroff and his colleagues described environmental variables that were correlated with SES but were not equivalents (Sameroff et al., 1998). These included:
1. Maternal mental illness
2. Parental perspectives
3. Unskilled occupation
4. Disadvantaged minority status
5. Large family size.

The researchers then compared subgroups of high- and low-risk children identified on these variables. The low-risk group had higher (better) cognitive and mental health outcomes on each of the variables than did the high-risk group. Group differences, however, were relatively moderate, "certainly not enough to detect which specific individuals with the risk factor would have an adverse outcome" (p. 165).
Commonly identified risk signs are shown in Table 2. Note that many describe demographic variables.

Findings from the Nichols and Chen (1981) follow-up of over 38,000 children who were part of the National Collaborative Perinatal Project (NCPP) are instructive in this regard. Their findings are notable because of the large and geographically representative sample. Learning difficulties were strongly associated with demographic variables such as large family size, low SES, and frequent changes in residence.

In the Nicols and Chen work, demographic variables also were associated with hyperactive/impulsive (HI) behavior and evidence of minimal brain dysfunction (MBD). Race was not a significant discriminator when SES and demographic variables were controlled.

It should be noted, however, that in the United States, more minority than non-minority children live in poverty, leading to a higher incidence of risk in minority groups. The Nichols and Chen findings of the relatively high frequency of academic and behavior problems of children from lower SES homes have been supported by the work of other investigators (e.g. Grizenko, \& Pawluk, 1994; Ramey \& Campbell, 1992).

As discussed earlier, prediction from risk factors alone is not sufficient as protective or promoting factors also influence outcomes. Commonly identified protective factors are shown in Table 3. Most of these factors describe conditions that are associated with SES, and many are the opposite of the risk factors found in Table 2 (e.g., safe or unsafe neighborhood, stable residence/frequent changes in residence).

TABLE 2 Family Risk Variables
Low SES-poverty
Unsafe neighborhood
Low parent education
Large family size
Children closely spaced
Overcrowded home
Frequent changes in residence
Frequent parent absence
Mother's mental health
Parent criminality
Parent substance abuse

Source: From Minimal Brain Dysfunction by P. L. Nichols \& T-C Chen (Hillsdale, NJ: Lawrence Erlbaum \& Associates, 1981); Risk and Protective Factors in the Lives of Children with High-incidence Disabilities, by E. E. Werner, in Developmental Perspectives on Children with High-incidence Disabilities (Mahwah, NJ: Lawrence Erlbaum Assoc., 1999). Pp. 15-22. 


\section{TABLE 3 Family Protective Variables}

\author{
Safe neighborhood \\ Stable residence \\ Adequate income \\ Fewer than four children \\ Spacing between children \\ Parents present \\ Good mental and physical health (parents) \\ Kin and alternative caregivers available \\ Services available
}

\begin{abstract}
Source: From Protective Factors in Children's Responses to Stress and Disadvantage by M. Rutter, in M. W. Kent and J. E. Rolf (Eds.) Primary Prevention of Psychopathology (Hanover, VT: University Press of New England, 1979). Pp. 49-72. No Concept of Risk from a Developmental Perspective by E. E. Werner, in B. K. Keogh (Ed.) Advances in Special Education Vol. 5: Developmental Problems in Infancy and the Preschool Years (Greenwich, CT: JAI Press, 1986). Pp. 1-23.
\end{abstract}

Given the well established findings of significant associations between SES and subsequent educational achievement, it is tempting to view SES as a causal condition. But it is important to emphasize that many children in low-SES homes grow up in positive environments, have close and stable families, and have good role models and mentors. -Although limited economically, these homes provide protective influences that enhance children's development and well-being. Three points are to be emphasized:

1. SES is not an explanatory concept but, rather, captures a cluster of conditions.

2. Outcomes within groups classified on SES criteria vary widely.

3. Problems in development and achievement are evident across the full SES range.

Clearly, conditions captured by demographic indicators are powerful contributors to risk, as evidenced for groups of individuals, but they do not explain differences in outcomes for individuals within groups. Predicting outcomes for individual children in SES-identified groups is "iffy" at best.

Note that most of the risk and protective factors shown in Tables 2 and 3 describe distal aspects of families and homes. Although these are important characteristics, they do not provide insights about how families function. To understand what happens in families, it is necessary to get to more proximal levels of information. How families function differs greatly among families identified on demographic characteristics, and these differences are not necessarily related to SES.
Almost 30 years ago, Baumrind (1971) described three types of parenting styles that subsequently were found to be associated with children's achievement:

1. Authoritative

2. Permissive or laissez-faire

3. Authoritarian.

Hechtman (1991) suggested that homes characterized by "warmth and support.... where emotional expressions, open communication and independence are encouraged" (p. 418) were likely environments for the development of resilient children. In their seminal longitudinal study, Werner and Smith (1992) found a number of characteristics of children and their families to be associated with positive outcomes for the individuals more than 30 years later.

The affective climate of the home and the nature of caregiver practices are important, as these make up the ongoing content of family life. Like the risk and protective variables shown in Tables 2 and 3, however, family climates are summarizing terms and do not necessarily capture the functional interactions within families. Rende and Plomin (1993) stressed the importance of understanding the "proximal variables that reflect environmental processes that reflect the risk factors for individuals" (p. 531). The daily interactions between children and parents over time likely are the basis for these process variables.

Consistent with this kind of thinking, in longitudinal research at UCLA, we have studied children identified as "at-risk" in the preschool years and their families over a 20year period, documenting the ways in which families organize their lives. We have found that the functional and ongoing interactions of children and their families are captured in the family daily routine. By "daily routine," we mean the everyday, mundane, common "stuff" of family life, the "things that are done and the things that are not done" (Bernheimer \& Keogh, 1995). Everyday activities comprise the content of family life and are the basis for parent-child interactions and, thus, for children's learning and self-views.

Rutter (1984) suggested, for example, that children learn problem-solving skills by watching how their parents deal with everyday matters. Masten, Best, and Garmezey (1991) proposed that a child's mastery motivations and self-esteem develop within a family context, as parents provide opportunities for learning and serve as behavioral models. Sigel (1998) argued that prerequisites for schooling are acquired through parents as socializing agents, and specifically through verbal interactions between parents and children.

Based on their studies of "at-risk" families, Ramey, Ramey and Lanzi (1998) identified six "psychosocial mechanisms" 
or "priming mechanisms" related to intellectual and social changes in children and adults in poverty circumstances:

1. Opportunities to explore and gather information

2. Being mentored in new skills

3. Celebration of developmental achievements

4. Review and rehearsal of new skills and knowledge

5. Avoidance of inappropriate punishment and ridicule

6. Language as a mechanism for learning.

\section{These researchers concluded that}

\begin{abstract}
there are systematic and practically important differences among poverty families with respect to their children's levels of academic and social risk. This finding is a necessary prelude to the more intriguing question: What kind of interventions work best for whom?" (p. 203)
\end{abstract}

In summary, a number of risk and protective conditions in families have been shown to affect children's development and achievement. Yet, families are only part of the context of children's lives. School is a second major component of context, a context that most children experience for a good many years. Despite many common aspects, their experiences in school vary widely and the contributions of schooling to their intellectual progress and their social adjustment differ. For some, school is a safe haven; for others, it is an ongoing nightmare. Like child-family interactions, schooling brings together characteristics of children and characteristics of the environment. Some fit well together, and others are discordant. It is important, therefore, to consider risk and protective influences in schools.

\section{School Risk and Protective Influences}

The current emphasis on improving educational outcomes has illuminated major differences among schools, and research on schools and schooling is receiving increased attention and support. Research on and in schools is slow work, and a number of methodological problems have to be addressed (see Maughan, 1988, for discussion).

First, what should be assessed and how should schooling be measured? Children's characteristics and their educational outcomes have been limited, for the most part, to narrow, normative measures, such as standardized aptitude and achievement tests. Test scores allow the designation of students as failing or successful, as risk or non-risk, but do not necessarily provide insight into the mechanisms or processes that account for these outcomes.

Second, when schools are taken into account, they often are treated as if they represent a single main effect when in fact they vary greatly within and across school districts. Thus, we cannot assume homogeneity of effects.

Third and finally, most studies have used cross-sectional or short-term longitudinal designs, and the nature of the interactions and transactions over time is not known. Despite such problems, a number of characteristics of effective and less effective schools have been identified. Examples of risk conditions are shown in Table 4.

Analogous to understanding risk within families, it is important to emphasize that not all children in high-risk schools have poor achievement and adjustment, and that many schools within risk areas function well. As in families, certain protective factors characterize schools. Commonly identified protective factors are summarized in Table 5 .

The characteristics shown in Tables 4 and 5 have potentially powerful influences on children's academic and personal development. Even though these risk and protective factors are well known, like many descriptors of families,

\section{TABLE 4 School Risk Variables}

High crime area
Physically unsafe
Overcrowded classrooms
Inadequate materials and supplies
Frequent changes in staff
High rate staff absenteeism
Frequent moves by pupils
High-rate pupil absenteeism
Few resources or special programs
Many low-ability/achieving peers

Source: From Risk and Protective Factors and Achievement of Children at Risk by D. V. Krasner (Doctoral Dissertation: Graduate School of Education, UCLA, 1992). Pp. 1-124. Fifteen Thousand Hours: Secondary Schools and their Effects on Children (London: Open Books, 1979).

\section{TABLE 5}

\section{School Protective Variables}

\author{
Physically safe \\ Low-crime area \\ Not overcrowded \\ Adequate materials and supplies \\ Stable staff \\ Low absenteeism (staff and pupils) \\ Special resources and programs available \\ Adequate/high-ability peers
}

Source: From Risk and Protective Factors and Achievement of Children at Risk by D. V. Krasner (Doctoral Dissertation: Graduate School of Education, UCLA, 1992). Pp. 1-124. Fifteen Thousand Hours: Secondary Schools and their Effects on Children (London: Open Books, 1979). 
they tend to identify structural, demographic aspects of schools. Further, until recently only limited research has been done on the functional aspects of how risk and protective influences work.

Many of the risk and protective aspects of schools shown in Tables 4 and 5 are well known and require little discussion. Clearly, safety is important; quality programs require adequate and appropriate materials. Yet, in some schools, especially schools in low-income communities, children are at-risk educationally because buildings are rundown, physical safety is questionable, and students do not have needed instructional materials. These conditions compound the developmental and educational status of at-risk children. The importance of safe and adequate school environments is not a scientific question that requires more research. Rather, it tests our social/political commitment to children and education.

\section{FUNCTIONAL ASPECTS OF SCHOOLS}

Like families, schools may be categorized according to demographic indicators. Also like families, as noted earlier, schools vary greatly when defined demographically. This, of course, underscores the importance of understanding how individual schools function. Important domains of schools have been specified in a number of major studies (National Education Longitudinal Study, 1988). These include instructional programs, administrative practices, and school environments and climates-domains that are consistent with the findings from research on schooling effects on at-risk students (Rutter \& Madge, 1976).

In this article I focus on the impact of three functional aspects of classroom environments on children's school experiences, arguing that risk status is, in part at least, a function of "goodness of fit" between child attributes and schooling demands (Keogh, 1982, 1986). Marginal or risk pupils in the early years likely are especially vulnerable to schooling effects, including instructional and curricular demands and teachers' perceptions and expectations.

\section{Instructional Programs}

Children bring different aptitudes, motivations, and personal competencies and problems to school. These personal characteristics interact with the programs provided-in some cases leading to successful learning and in others resulting in failure to learn. This perspective on risk clearly broadens the conceptualization of risk and has implications for assessment and instruction. Too often, failure to learn is attributed to limitations of children and families (e.g., "He's not learning because he lacks ability," "She's unmotivated," or "His parents don't value education"). Alternatively, the problem may be based in the fit between child and program or viewed as "instructional failures."
This issue is well illustrated by the ongoing "reading wars" that pit whole-word methods against phonologically based methods. Advocates of each argue that their method is better, implying that a certain method is effective for all children. Common sense, as well as accumulating evidence, suggests that both approaches have merit with some, but not all, children.

Major research programs under the auspices of the National Institute of Child Health and Human Development (NICHD) provide compelling evidence of the effectiveness of phonologically based instruction for most beginning readers and many children with reading problems (see Lyon, 1995; Lyon, Alexander, \& Yaffe, 1997, for reviews). Less is known about instruction directed at reading comprehension and fluency, or about the development of literacy (see Pressley et al., 2000). Further, almost all programs report that a small percent of children are nonresponders resistant to treatment. They do not learn to read even when effective interventions are implemented.

To date, there is limited understanding of the interactions between instructional methods and the characteristics of the children so instructed. Some children enter school with good phonemic awareness skills, having already mastered the alphabetic code. Others are woefully behind in these skills and need intense and specific instruction. The point to be emphasized is that both child characteristics and instructional methods must be included in the learning equation. This point is particularly relevant for children who enter school at-risk, as they may not have had the opportunities and experiences provided their more advantaged peers, and, thus, may be especially sensitive to the instructional program.

Effects on students' learning also are seen in the ways in which the content of instruction is delivered. Some children receive more teacher attention than others, as teacher time is not spread equitably across all students in a classroom. Some programs are individualized, but most rely on whole class instruction.

Zigmond and her colleagues have used both qualitative and quantitative methods to study classrooms (see Zigmond, 1996, for a review of this work). A study of 12 general education classrooms revealed that there was little if any differentiated instruction and that teachers "were more committed to routine than to addressing individual differences, and that they were more responsive to district mandates than to evidence from their students that the curriculum or pacing needed to be adapted" (p. 165). In further studies, these researchers also found that most instruction was targeted at the modal student, suggesting that the level of instruction might be inappropriate for students at the upper and lower ends of the achievement distribution.

I emphasize that teachers are not solely responsible for students' academic progress, as they struggle with many 
constraints on their opportunity to teach. Rather, problems for at-risk children reflect systemwide conditions.

\section{Curriculum}

Despite the call for individualization of instruction, many school districts determine curriculum content according to grade level-that is, according to what students ought to learn at given ages. Teachers are obligated to cover the materials so defined. Yet the demands of the curriculum may not be consistent with at-risk students' skills. I illustrate with two children who live in a homeless shelter in a major city. Both are of ethnic-minority backgrounds, both attend public elementary schools, and both have normal ability as evidenced in everyday competencies.

The 6-year old boy is being promoted to second grade, but his reading is limited to a half dozen simple words (e.g., cat, dog). The reading curriculum in the last months of his first grade consisted of work on endings (ings and eds)content that clearly was beyond his reading level. The 12year old girl is an adequate reader, but her arithmetic skills are limited to basic addition and subtraction. She cannot do long division or multiply two-digit numbers. The arithmetic curriculum in her class focused on decimals and fractions.

Both of these children have potential for learning but are in situations where their skills are so discrepant from the content of the curriculum that they face daily failure. The girl's reaction to the discrepancy between her arithmetic skills and the demands of the curriculum was to become increasingly passive and to give up. The boy has started to act out already. Both children have potential but are slipping behind in programs that are discrepant from their functional levels in specific content areas. They are increasingly at risk.

\section{Teachers' Perceptions and Expectations}

Other influences on how classrooms function have to do with teachers' goals and expectations for students' performance. Teachers differ in their knowledge of subject matter, in their instructional practices, and in the ways they organize classrooms. They also differ in their personal attributes, attitudes, and beliefs, as well as in the expectations they have for children's behavior and achievement. These differences may serve as protective or risk influences, as some teachers are able to buffer children's problems and others may enhance or exacerbate problem conditions.

In classroom observational studies, UCLA researchers have shown that both the frequency of interactions and the nature of the interactions between teachers and students are related to teachers' beliefs about children's potential for achievement and students' personal attributes, including temperament (Keogh, 1982; Keogh \& Burstein, 1988). For some children the interactions with teachers are positive and social, and for others the teacher-child interactions are limited primarily to management. Children may be at increased risk because teachers have low expectations for performance related to ethnic or cultural factors, or because of the children's personal characteristics and behavioral styles. Students with easy temperaments are more likely to have positive interactions with teachers than are children with difficult temperaments (Keogh, 1986).

\section{THE ECOLOGY OF CLASSROOMS AND SCHOOLS}

The importance of classroom and school environments for at-risk students is well documented in current research and has led to increased interest in the ecology of schools (see Speece \& Keogh, 1996). Schools and children alike may be at-risk. In the name of accountability, it is easy to hold teachers and schools responsible for children's learning problems, and to assume that the effectiveness of schools may be measured with standardized achievement tests. It is important to emphasize, however, that schools are complex social systems, and to understand the long-term outcomes for children at-risk, we must take into account the functional nature of schools. This means going beyond the usual quantitative, summarizing descriptors (e.g. size, SES) to get a more complete picture of what actually happens in school classrooms.

A number of questions about risk and protective factors in schools require further research. These include issues related to programmatic modifications and the long-term consequences of given risk conditions. Other aspects of schools, however, require immediate action, not research. These have to do with issues of safety, the school environment, and the need for well trained teachers and adequate instructional materials. Overcrowded classrooms, in which children are in close physical proximity, and inadequate materials and supplies are risk conditions that may contribute to children's educational and social/behavioral problems. These are risks that we can modify and improve through commitment of resources and energy.

\section{RESILIENCE}

Any discussion of risk would not be complete without considering the notion of resilience. Resilient children are those who develop well even in conditions that for most lead to negative outcomes. Masten, Best, and Garmezy (1991) defined resilience as "the process of, capacity for, or outcome of successful adaptation despite challenging or threatening circumstances." (p. 426). They noted that protective factors may moderate the negative impact of personal or environmental conditions.

Smith and Prior (1995) considered resilience to be the "capacity to maintain healthy functioning in an unhealthy setting, or the maintenance of mastery under stress" (p 168). 
They stated further that "resilience presumes a capacity of the individual child to recover, bounce back, or remain buoyant in the face of adversity, life stresses, illness, misfortune, and the like."

Richmond and Beardslee (1988) noted that resilience is "successful coping or adaptation or mastery" (p. 157). Egeland, Carlson, and Sroufe (1993) viewed resilience as process and emphasized the interactions and transactions that lead to developmental outcomes. Rutter (1989) concurred, noting that resistance to stress is relative, not absolute, and that the degree of resistance varies over time and according to life circumstances.

Certainly there are many examples of children who have managed well despite stressful and negative conditions that resulted in damaging outcomes for their peers. Werner and Smith (1989) found about one in 10 of their sample to be resilient. An interesting question is: What accounts for their good outcomes? A number of personal and environmental conditions characterized the resilient children in the Werner and Smith research. Early on, they were active and socially responsive, had strong attachment to their mothers, good self-help skills as toddlers, and effective problem-solving and communication skills in the middle years. Compared to peers, they experienced fewer life stresses and had networks of friends, both peers and adults. Their caregiving conditions were generally positive, including cohesiveness of the family.

In their longitudinal Australian study, Smith and Prior (1995) found that resilient and nonresilient children differed on personal characteristics, including temperament, although all were in stressed or "risk" environments. Similar to the Werner and Smith (1989) findings, resilient Australian children were socially responsive, attractive to other people, easy-going, even-tempered, and not easily distressed. Smith and Prior emphasized that temperamental characteristics influenced both positive (social competencies) and negative (behavioral adjustment) outcomes.

Clearly, resilience is not a single, unitary concept but, rather, involves a number of personal capacities and conditions (Masten et al., 1991). Resilient children are described as having easy and positive temperaments, as "engaging," characteristics that likely smooth the nature of their interactions with others. Because they are good problem-solvers and good learners, they are able to deal effectively with difficult situations. They are competent in areas that others value, which provides positive feedback and reinforces their sense of competence. But children live in families and go to school, so the context of their lives also must be considered. We should expect that changes related to development, age, and gender, and therefore predictions about long-term outcomes for resilient young children, like those about children at risk, must be made cautiously.
The focus on resilience provides a needed and important direction to research on risk, as it moves us away from the traditional emphasis on pathology and negative outcomes (Garmezy, 1985). Rather, interest in resilience forces us to consider a broad array of influences which lead to healthy development and adjustment. Many of the processes accounting for resilience have not been specified, nor is the nature of their interactions known. There is, however, a clear move toward identifying the factors which lead to positive outcomes for at risk individuals. These include contextual conditions such as families and schools, as well as personal characteristics.

In a recent publication (Keogh, in press) I cite the comments of Norman Garmezy, who wrote the Foreword to Werner and Smith's book, Vulnerable But Invincible (1989): "Were we to study the forces that move children to survival and to adaptation, the long-range benefits to our society might be far more significant than are the many efforts to construct models of primary prevention to curtail the incidence of vulnerability" (p. xix). His wise words provide direction to the work to be done to improve our understanding of risk in children's lives.

\section{REFERENCES}

Baumrind, D. (1971). Current patterns of parental authority. Developmental psychology monographs, 4 (1, Part 2).

Bernheimer, L.P. \& Keogh, B.K. (1995). Weaving interventions into the fabric of everyday life: An approach to family assessment. Topics in Early Childhood Special Education, 15, 415-433.

Egeland, B., Carlson, E. \& Sroufe, L.A. (1993). Resilience as process. Development \& Psychopathology, 5, 517-528.

Garmezy, N. (1985). Stress-resistant children: The search for protective factors. In J. E. Stevenson (Ed.), Recent research in developmental psychopathology. Journal of Child Psychology \& Psychiatry Book (Supplement No. 4), 213-233.

Garmezy, N. (1989). Foreword. In E.E. Werner, Vulnerable but invincible (pp. xiii-xix). New York: Adams, Bannister, Cox.

Garmezy, N., Masten A., \& Tellegen. A. (1984). The study of stress and competence in children: A building block for developmental psychopathology. Child Development, 55, 97-11.

Grizenko, N. \& Pawliuk, N. (1994). Risk and protective factors for disruptive behavior disorders in children. American Journal of Orthopsychiatry, 64, 534-544.

Hechtman, L. (1991). Resilience and vulnerability in long term outcome of attention deficit hyperactive disorder. Canadian Journal of Psychiatry, $36,415-421$.

Keogh, B. K. (1982). Children's temperament and teachers' decisions. In R. Porter \& G. Collins (Eds.), Temperamental differences in infants and young children, (pp. 269-279). London: Ciba Foundation/Pitman.

Keogh, B. K. (1986). Temperament and schooling: What is the meaning of goodness of fit? In J. V. Lerner \& R. M. Lerner (Eds.), Temperament and social interaction during infancy and childhood: New directions for child development, No. 31 (pp. 89-108). San Francisco: JosseyBass.

Keogh, B.K. (In press). Understanding risk for learning and development. Learning Disabilities: A Multidisciplinary Journal. 
Keogh, B.K. \& Bernheimer, L.P. (1995). Etiologic conditions as predictors of children's problems and competencies in elementary school. Journal of Child Neurology, 10 (Supplement Number 1), 100-105.

Keogh, B.K., Bernheimer, L. P., \& Weisner, T. (2000). UCLA research in progress.

Keogh, B.K. \& Burstein, N.D. (1988). Relationship of temperament to preschool children's interactions with peers and teachers. Exceptional Children, 54(5), 456-461.

Keogh, B. K. \& Weisner, T. (1993). An ecocultural perspective on risk and protective factors in children's development: Implications for learning disabilities. Learning Disabilities Research \& Practice, 8, 3-10.

Krasner, D. V. (1992). Risk and Protective Factors and Achievement of Children at Risk. Unpublished Doctoral Dissertation, UCLA.

Lewis, M., \& Feiring, C. (1998). Families, risk, and competence, Mahwah, NJ: Erlbaum.

Lyon, G.R. (1995). Research initiatives in learning disabilities: Contributions from scientists supported by the National Institute of Child Health and Human Development. Journal of Child Neurology, 10, 120-127.

Lyon, G.R., Alexander, D., \& Yaffe, S. (1997). Progress and promise in research in learning disabilities. Learning Disabilities: A Multidisciplinary Journal, 8, 1-6.

Masten, A.S., Best, K.M., \& Garmezy, N. (1991). Resilience and development: Contributions from the study of children who overcome adversity. Development \& Psychopathology, 2, 425-444.

Maughan, B. (1988). School experiences as risk/protective factors. In M. Rutter (Ed.), Studies of psychosocial risk: The power of longitudinal data. Cambridge, MA: Cambridge University Press.

National Educational Longitudinal Study (NELS). (1988). Washington, DC: U.S. Department of Education, National Center for Educational Statistics.

Nichols, P. L., \& Chen, Ta-Chuan. (1981). Minimal brain dysfunction. Nahwah, NJ: Lawrence Erlbaum Associates.

Pressley, M., Wharton-McDonald, R., Allington, R., Block, C.C., Morrow, L., Tracey, D., Baker, K., Brooks, G., Cronin, J., Nelson, E., \& Woo, D. A study of effective first grade literacy instruction. Scientific Studies in Reading. In press.

Ramey, C. T., \& Campbell, F.A. (1992). Poverty, early childhood education, and academic competence. The Abecedarian experiment. In A. Huston (Ed.), Children in poverty. New York: Cambridge University Press, 190-221.

Ramey, C. T., Ramey, S. L., \& Lanzi, R. G. (1998). Differentiating developmental risk levels for families in poverty: Creating a family typology. In M. Lewis \& C. Feiring (Eds.), Families, risk, and competence (pp. 187-206). Mahwah, NJ: Lawrence Erlbaum.

Ramey, C., Trohanis, P.L., \& Hostler, C. (1982). An introduction. In C. Ramey \& P.L. Trohanis (Eds.), Risk in infancy and early childhood (pp. 1-18). Baltimore: University Park Press.

Rende, R., \& Plomin. R. (1993). Families at risk for psychopathology: Who becomes affected and why? Development \& Psychopathology, 5, $529-540$.

Richmond, J. B., \& Beardslee, W.R. (1988). Resilience: Research and practical implications for pediatricians. Developmental \& Behavioral Pediatrics, 9, 157-163.

Rutter, M. (1979). Protective factors in children's responses to stress and disadvantage. In M.W. Kent \& J.E. Rolf (Eds.), Primary prevention of psychopathology: Vol 3. Social competence in children (pp. 49-72). Hanover: VT: University Press of New England.
Rutter, M. (1984). Resilient children. Psychology Today, Vol. 18, 57-65. Rutter, M. (1987). Psychosocial resilience and protective mechanisms. American Journal of Orthopsychiatry, 57, 316-331.

Rutter, M. (1989). Psychosocial resilience and protective mechanisms. In J Rolf, A.S. Masten, D. Cicchetti, K. H. Nuechterlein, \& S. Weintraub, (Eds.), Risk and protective factors in the development of psychopathology (pp. 161-214). New York: Cambridge University Press.

Rutter, M., \& Madge, N. (1976). Cycles of disadvantage: A review of research. London: Heinemann.

Rutter, M., Madge, N., Mortimore, P., Orston, J., \& Smith, A. (1979). Fifteen Thousand Hours: Secondary Schools and their effects on Children. London: Open Book.

Sameroff, A.J., Barto, W.T., Baldwin, A., Baldwin, C., and Siefer, R. (1998). Family and child influences on the development of child competence. In M. Lewis \& C. Feiring (Eds.), Families, risk, and competence (pp. 161-186). Mahwah, NJ: Lawrence Erlbaum.

Sameroff, A., \& Chandler, M. (1975). Reproductive risk and the continuum of caretaking casualty. In F.D. Horowitz (Ed.), Review of child development research (Vol. 4,187-244). Chicago: University of Chicago Press.

Sameroff, A., Seifer, R., Baldwin, A., \& Baldwin. C. (1993). Stability of intelligence from preschool to adolescence: The influence of social and family risk factors. Child Development, 64, 80-97.

Sigel, I.E. (1998). Socialization of cognition: A family focus. In M. Lewis \& C. Feiring (Eds.), Families, risk, and competence (pp. 289-307). Mahwah, NJ: Lawrence Erlbaum.

Smith, J. \& Prior, M. (1995). Temperament and stress resilience of schoolage children: A within-families study. Journal of Child Psychology \& Psychiatry, 34, 168-179.

Speece, D. L., \& Keogh, B. K. (Eds.). (1996). Research on classroom ecologies: Implications for inclusion of children with learning disabilities. Mahwah, NJ: Lawrence Erlbaum.

Werner, E. E. (1986). The concept of risk from a developmental perspective. In B.K. Keogh (Ed.), Advances on special education: Vol. 5. Developmental problems in infancy and the preschool years (pp. 1-23). Greenwich, CT: JAI Press.

Werner, E. E. (1993). Risk and resilience in individuals with learning disabilities: Lessons learned from the Kauai longitudinal study. Learning Disabilities Research and Practice, 8, 28-34.

Werner, E. E. (1999). Risk and protective factors in the lives of children with high-incidence disabilities. In R. Gallimore, L.P. Bernheimer, D.L. Macmillan, D.L. Speece, \& S. Vaughn (Eds.), Developmental perspectives on children with high-incidence disabilities. Mahwah, NJ: Lawrence Erlbaum, pp.15-32.

Werner, E. E. \& Smith, R. (1989). Vulnerable but invincible: A longitudinal study of resilient children and youth. New York: McGraw-Hill.

Werner, E. E., \& Smith, R.S. (1992). Overcoming the odds: High risk children from birth to adulthood. New York: Cornell University Press.

Zigmond, N. (1996). Organization and management of general education classrooms. In Spece, D. K., \& Keogh, B. K. (Eds.), Research on classroom ecologies: Implications for inclusion of children with learning disabilities (pp. 163-190). Mahwah, NJ: Lawrence Erlbaum.

Parts of this article were included in a presentation at the Lab School of Washington Conference on "Who Is the Child At-Risk?" Washington, DC, October 13, 2000. 


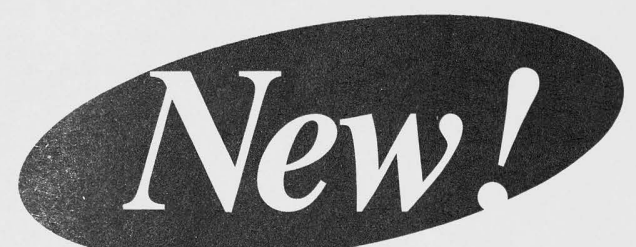

\title{
Functional Behavioral Assessment
}

\section{A Systematic Process for Assessment and Intervention in General and Special Education Classrooms}

\author{
Mary E. McConnell, Turner School District, Kansas City, Kansas
}

Functional assessment can be overwhelming to educators who are not familiar with the process. This book is designed specifically for persons who have limited training in applied behavior analysis and functional assessment procedures.

This easy-to-use manual will help educators understand the purpose and meaning of the functional behavior assessment process and how to identify and assess behavior. It shows how to develop and write effective Behavior Intervention Plans using data collected during the functional assessment.

\section{SPECIAL FEATURES}

- Presents step-by-step procedures for conducting functional assessments

- Shows how to write Behavior Intervention Plans and select interventions

- Discusses data collection

- Includes dozens of checklists and plan sheets for working with Behavior Intervention Plans.

\section{CONTENTS}

1. Introduction to IDEA and Functional Assessment

2. The Function of Functional Assessment

3. Functional Assessment Process

4. Behavioral Intervention Plans

5. Appendix Forms and Planning Sheets

112 pages/0009/paperback/81/2 x 11/ISBN 0-89108-277-8/\$24.95

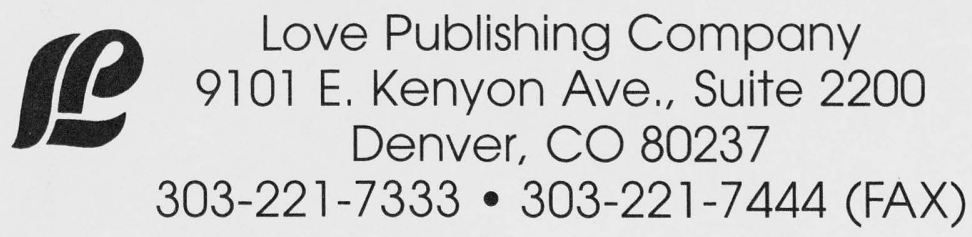




\section{Professional update}

\section{Learning Disabilities Association of America}

February 7-10, 2001

New York Hilton Hotel

New York, NY

Contact: LDA

4156 Library Road

Pittsburgh, PA 15234

(412) 341-1515

Midwest Symposium for Leadership in Behavior

Disorders Symposium 2001: Our Children's Odyssey

February 22-24, 2001

Hyatt Regency Crown Center

Kansas City, MO

Contact: Kirsten McBride

(913) 492-8755

Fax: (913) 492-2546
American Educational Research Association

April 10-14, 2001

Seattle, WA

Contact: (202) 223-9485

http://www.aera.net

National Association of School Psychologists

April 17-21, 2001

Washington, DC

Contact: (301) 657-0270

http://www.naspweb.org

Council for Exceptional Children

April 18-21, 2001

Kansas City, MO

Contact: (800) 486-5773

http://www.cec.sped.org

\section{PERMISSIONS AND COPYRIGHT}

All rights are reserved. No part of this publication may be reproduced, photocopied, faxed, stored in a retrieval system, or transmitted in any form or by any means, electronic, mechanical, recording or otherwise, without the prior written permission of the publisher.
Back issues are available for sale. Reproduction requires permission and payment of fees. It is illegal and a violation of federal copyright law to reproduce this publication without permission. Direct all inquiries to the permissions editor. 